\title{
Stock prices and demand for money in China: new evidence.
}

\begin{abstract}
This paper investigates the relationship between stock prices and the real money demands for China within a cointegrated framework. This study reports two important results. First, test results reveal that a stable long-term relationship exists between broad money (M2) and its determinants including real income, foreign interest rate, and stock prices. Second, stock prices have a significant substitute (positive) effect on long-run broad-money (M2) demand and its omission can lead to serious misspecification in the money demand function in both the short- and long-run. Finally, we demonstrate that long-run income elasticity is not significantly different from unity with the inclusion of stock prices in the money demand equation.
\end{abstract}

Keyword: Real M2 money demand; Cointegration test. 